\title{
A Review of Researches on Sleepiness at Workplace
}

\author{
Xiang Jiao, Maolin Ye \\ School of Management, Jinan University, Guangzhou, China \\ Email:wave105@163.com
}

Received 13 June 2016; accepted 1 August 2016; published 4 August 2016

Copyright (C) 2016 by authors and Scientific Research Publishing Inc.

This work is licensed under the Creative Commons Attribution International License (CC BY). http://creativecommons.org/licenses/by/4.0/

c) (i) Open Access

\begin{abstract}
Sleepiness at workplace, the biological drive to sleep, has a highly negative impact on employees' working behavior in organizations. Recently, this phenomenon has attached more and more attention in the management filed; and it has attracted much attention of researchers from other fields, such as management and psychology. By reviewing and analyzing the previous studies, this paper clarifies the concepts of sleepiness in the workplace, and then delineates the causes and effects of sleepiness in the workplace. Through the organizational understanding of the relevant causes of sleepiness, some intervention measures which can mitigate companies' sleepiness situation will be put forward. Finally, the paper has an outlook about the future researches of sleepiness at workplace.
\end{abstract}

\section{Keywords}

\section{Sleepiness at Workplace, Job Performance, Accident Rate, Job Rotation}

\section{Introduction}

Nowadays, management and psychology have expanded its focus on the impact of non-work variables on job performance, and especially on the relationship of sleep and job performance. As we all know, adults spend most of their time on work and sleep, but there is little exploration of the relationship between these two. In recent years, scholars in the field of management and applied psychology have gradually focused on the relationship between sleep and work, and conducted some empirical researches. These studies show that the most common sleep problem is the phenomenon of sleepiness. That is, whenever and wherever, it is accompanied by a desperate desire to sleep. Sleepiness seems to be a simple concept, but if it occurs in the workplace, then it will lead to lots of negative effects. For example, when driving, the driver will cause a serious traffic accident due to sleepiness; in the steel industry, workers can also cause serious accidents because of sleepiness. However, in 
China, scholars only explored the effects of sleep restriction and sleep deprivation on the body from the perspective of clinical medicine, such as, their impact on the human nervous system, immune system, and biochemical indicators [1]. And few scholars discuss the influence of sleep problems in workplace on work results. Therefore, it is necessary to comprehensively outline the domestic and international researches on sleepiness at workplace, which is of great practical and theoretical significance. By reviewing and analyzing the previous studies, this paper will clarify the concepts of sleepiness in the workplace, and then delineate the causes and effects of sleepiness in the workplace. Through the organizational understanding of the relevant causes of sleepiness, some intervention measures which mitigate companies' sleepiness situation will be put forward. Finally, the paper has an outlook about the future researches of sleepiness at workplace.

\section{Sleepiness Defined}

Throughout the research history of sleepiness, the concept has not yet formed a unified conclusion. In the most basic sense, researchers adopted Dement and Carskadon perspectives that sleepiness can be defined as "a craving or desire for sleep” [2]. Recently, the meta-analysis of sleep issue showed that the sleepiness included difficulties to wake up, problems to stay awake and falling asleep during daytime [3]. For the working people, the occurrence of sleepiness depends on sleep quality, sleep duration, the circadian rhythms, and substances and CNS disorders. Therefore, Sleepiness can be defined as a phenomenon of desperate desire to sleep resulted from poor sleep quality, shortened sleep duration, the disordered circadian rhythm and the factors that act on the central nervous system [4].

This paper will combine the previous researches about the definitions of sleepiness with the unique field of workplace, and then come to the concept of sleepiness at workplace. That is, sleepiness at workplace is a phenomenon of desperate desire to sleep resulted from sleep lacking, poor sleep quality. And this paper will review and analysis the previous studies about sleepiness based on the above concepts.

\subsection{Sleepiness and Narcolepsy}

Narcolepsy and sleepiness at workplace have the essential differences in terms of definition, and so can't be confused. Narcolepsy is a neurological disorder, neither caused by sleep lacking, drugs, alcohol, somatic diseases, or it is a mental disorder symptoms. The peak of its incidence is at the age of 10, its characteristic symptoms include excessive daytime sleepiness, cataplexy and skeletal muscle paralysis [5]. At present, the medical profession generally believe that the narcolepsy maybe caused by genetic and environmental factors, including pressure. But the specific mechanism is not clear, and there is no cure method. The workplace sleepiness is simply the increase of sleep tendency at work, and it is not very serious compared with narcolepsy. In addition, the reasons of sleepiness are more specific, such as: sleep duration, the circadian rhythms, and substances and CNS disorders. Finally, a good sleep habit and regular nap can slow down the condition of sleepiness.

\subsection{Sleepiness and Fatigue}

The meanings of fatigue and sleepiness are very confusing, and the research time about fatigue is earlier than sleepiness. Some articles made clear distinctions about the relationship between sleepiness and fatigue. First, Fatigue is an overwhelming sense of tiredness, lacking of energy and a feeling of exhaustion, associated with impaired physical and/or cognitive functioning [6]. Sleepiness is that of one's tendency to fall asleep, also referred to as sleep propensity. Secondly, their antecedents are also different, fatigue is caused by time on task and cognitive load and is influenced by emotional state and immune state. And the occurrence of sleepiness depends on sleep quality, sleep duration, the circadian rhythms, and substances and CNS disorders. Finally, fatigue can be reversed by rest (e.g., time off task), while sleepiness can only be naturally (e.g., without the use of stimulants) reversed by sleep [7]. Thus, fatigue and sleepiness differ from each other in concepts, antecedents, and in the way that they are reduced. Furthermore, both of them have the same negative effects on production efficiency.

\section{Consequence of Sleepiness}

\subsection{Information Processing}

Decreases in activation of the brain regions which responsible for higher order cognitive abilities result in substantial deficits in information processing, particularly in the areas of processing speed, attention, learning and 
memory [8]. For this part, some scholars focus on sleepiness itself, while others focus on one of its immediate antecedents: sleep deprivation. Sleep deprivation results in deficits in information processing speed, which is evidenced by slower response times, increases in errors, and decreases the ability to correct errors. Moreover, the selective attention of individuals with sleep deprivation may also get worse, and compared to the later stage of information processing (e.g., response selection), the earlier stages of information processing (e.g., visual processing) will get a greater damage. In addition, sleep deprivation can decrease the level of activation in the hippocampus, which can affect the memory ability. In summary, sleepiness leads to poorer information processing through impacting on attention, processing speed, and memory. Sleepiness can interfere with the process of information processing by affecting the individual's attention, processing speed and memory. Information processing can be a mediator, and it will mediate the relationship between sleepiness at workplace and other variables. For example, sleepiness affects job performance through interference with information processing; it also affects individual attention, and eventually causing work accidents. However, the specific mediated interference process needs further empirical research.

\subsection{Affect}

Affect is a central construct in workplace psychology. Research has shown that sleepiness impacts individual affect. For instance, sleepy individuals have poor emotion regulation ability, and they can't deal with the negative emotions so that they fall into depression easily; sleepy individuals have more difficulties to moderate expression of happy and angry emotions; sleepy individuals are more easily distracted by negative emotional stimuli [9]. In addition, the antecedent of sleepiness has a direct impact on the affect. For example, poor sleep quality and sleep deprivation are related to a decrease in positive affect and an increase in negative affect [10]. So far, emotional variability (such as the decrease of positive affect and the increase of negative affect) has been studied by many scholars as the mediator between sleepiness and job satisfaction. Survey research showed that sleepy individuals are more likely to get angry, depressed, and have a low sense of accomplishment. Although the negative affect come from outside field of work, and they also have a negative evaluation of their work and lower job satisfaction [11]. Individuals with good sleep habits (e.g., sleep 6 hours or more a night on average) experience fewer depressive symptoms and experience a positive sense of purpose in life [12]. Therefore, affect is an important consequence of workplace sleepiness.

\subsection{Job Performance}

Job performance is a variable which is highly susceptible to individual sleepiness, and it is composed of task performance, adaptive performance and contextual performance. Task performance refers to the behavior and performance of individuals that can control and contribute to the achievement of organizational goals. Sleepiness impairs aspects of task performance related to reaction times, response accuracy, errors of omission, and lapses [13]. Adaptive performance refers to the behavior and performance of units within the organization (such as individual, group) that can effectively respond to the work demands in a dynamic environment [14]. Adaptive performance requires the capability to learn work tasks, technologies, and procedures, but sleepiness caused by sleep lacking may lead to decrements in learning or memory consolidation and to decrements in the ability to clear the old information, so that individuals are more difficult to adapt to the changing workforce [15]. Contextual performance refers to the support that individual provide to their colleagues and organizations as well as positive attitude towards work [16]. Because sleepy individuals are more likely to incorrectly recognize emotions such as anger or happiness, and social interactions rely on the accurate recognition of emotion, and individuals who are sleepy due to sleep loss may be more likely to incorrectly interpret social situations [17]. Therefore, the components of contextual performance that are dependent on affect and interpersonal skills are most likely to be affected by sleepiness.

\subsection{Accidents}

A workplace accident is a safety-related incident resulting in property damage, injury, or death [18]. When working, in order to avoid accidents, individuals must not be sleepy and keep vigilant at all times. Being sleepy will weaken the perception of visual stimuli, and delay the reaction time to increase the error prone, and ultimately lead to dangerous accidents [19]. Objective measurement of sleepiness resulting from common causes in 
the general population, such as insufficient sleep, has been found to predict police-verified automotive accidents [20]. In addition, the impact of sleepiness on the medical accident can't be ignored, and excessive work and lack of sleep will directly lead to medical accidents. Therefore, getting adequate sleep and proper rest is essential for doctors to reduce the medical accidents. Previous studies have investigated the sleep status of employees at night by self-report, and it reveals that sleep disorder at night will make employees have more serious sleepiness next day, and this kind of sleepiness can induce accidents [21].

\section{Antecedents of Sleepiness}

Now that we have discussed the negative effects that sleepiness brings to individuals and organizations. In this section, we will discuss the job demands (e.g., work schedules, time pressure, workload, and perceived control) that can impact a worker's experienced sleepiness. Through an understanding of the organizationally relevant antecedents of sleepiness, we can begin to develop interventions that will reduce the sleepiness of individuals within an organization.

\subsection{Time Pressure, Workload, and Perceived Control}

If the company demands individual to finish the excessive workload in a short time, then they will have a sense of pressure and anxiety, and further affect the quality of sleep, reducing sleep time, and ultimately increase the frequency of sleepiness at work. Åkerstedt, Knutsson, et al. (2002) found that keeping on thinking about work while after work predicted both disordered sleep and feeling tired once awakening [22]. De Lange et al. (2009) found that over time, cumulative exposure to high job demands and low perceived control was related to an increase in sleep-related problems (e.g., trouble falling asleep, waking up early in the morning) and that cumulative exposure to low job demands with high perceived control was related to the highest levels of sleep quality [23]. When exploring these relationships at the within-person level, it is found that employees were accompanied by a significant improvement sleep quality when they change from the higher job demands to the lower job demands. All in all, making the proper job demands will make employees develop good sleep habits, and have adequate sleep time, ultimately reducing the frequency of sleepiness at work.

\subsection{Work Schedules}

A large number of studies have indicated that there is a connection between the work length and work rotation to sleepiness. As we all know, non-traditional or flexible work arrangements are of great help to achieve employee performance and organizational benefits. But due to the changing of working time, these schedules often require individuals to work outside the traditional nine-to-five workday, which will certainly influence individual sleeping status [24]. Besides, Staff often have to work overtime in the evening or late night or on the weekends when they facing with emergency situations. For example, factory manager must come back to the factory to deal with the emergence; a heart disease specialist may be called up for emergency surgery in the late night. When the length of the workday is increased or the number of hours in the workweek is increased, which tends to reduce sleep hours that an individual needs per night. These schedules must shorten sleep duration and worsen sleep quality, and day by day it will cause serious sleepiness at work.

\subsection{Job Rotation}

Job rotation refers to the arrangement for staff to complete their workload in the day, evening or late night [25], and some researches have shown that job rotation is the main reason of sleepiness [26]. Job rotation consists of two types. One is fixed shifts, in which an individual only works a single assigned shift of days, evenings, or nights; another kind is rotating shifts, in which an individual rotates among day, evening, or night shifts. Scholars found that rotating shifts will lead to greatest impact on sleepiness, especially end-of-day shifts and beginof-night shifts [27]. Rotation work is bound to cause the disorder of the circadian rhythm, because it requires employees to work in normal sleep time [28]. Shift workers are awaking and working at their circadian nadir in alertness, but usually this time is suitable for sleeping. Shift workers have not sufficient time to recover from the severe sleep restriction due to excessive workload. Therefore, more job rotation is associated with more sleepiness at work. 


\section{Intervention}

So far, the construct of sleepiness at workplace is quite original. The research of the concept, the occurrence mechanism and the factor about sleepiness are still in the embryonic stage, and then there are still fewer studies on sleepiness at workplace. From existing researches, intervention for sleepiness at workplace can be divided into individual intervention and organization intervention. In the long run, the combination of the two will become the mainstream in the future.

\subsection{Individual Intervention}

On the individual level, previous studies have found that individuals often reduce their sleep time to engage in private activities, such as watching TV, playing games and playing mobile phone [29]. Full-time workers have no extra time to schedule their private activities, because they spend much time on work, so that they often reduce their sleep time to engage in private activities. Based on above, employees can reduce the arrangement of private activities, for example less time for watching TV, less time for playing games, less time for playing mobile phones, and go to sleep on time and keep enough sleep duration. That is, developing good sleep habits can contribute to reduce sleepiness. In addition, emotional regulation will also affect the individual sleep quality. Compared to the people in a bad mood, people in a good mood will have a higher sleep quality. Therefore, the individual must learn the appropriate skills to adjust their emotion, and positive emotion can contribute to the high quality of sleep. As is known to all, coffee is good for refreshing, a cup of delicious coffee can ease the sleepiness at work.

\subsection{Organization Intervention}

The potential of organizational intervention is great, but it is difficult to implement, because it's hard to get enough cooperation, time, money, and effort. As previously discussed, the important organizational factors that affect the sleepiness at work have overtime work, overload work, low control sense and job rotation. According to these, we can put four intervention measures. As follows, first of all, it is necessary to arrange moderate work time. The extra hours about work must be limited, and organizations can't blindly pursue the performance and ignore the potential drawbacks. Secondly, it is a key to arrange moderate workload. On the condition that staff completes their task with high quality on time, they won't be required to pay extra labor. Thirdly, giving more rights to employees is also very significant. Leaders can guide employees to work effectively and organization can provide the chance of train about working skills to them. Finally, arrangement rotation work according to personal preference. Because some people prefer to work at night while some others like to work during the day, and it is worth noting that employees must have adequate recovery time during the rotation. One possible intervention is that of providing the opportunity for napping. Although fewer than $5 \%$ of organizations currently have onsite nap rooms [30]. Napping may be able to reduce the effects of sleepiness and keep employees working hard.

\section{Development}

At present, there are few researches on the sleepiness at work, and there are still many aspects not developed very well. This paper suggests that the current studies of the sleepiness can be strengthened in the following aspects.

\subsection{Diversification of Research Methods}

From the research methods, there has not been an empirical study about the sleepiness at workplace. In the field of sleep study, scholars have developed the sleep scale of various subjective rating, such as Epworth sleepiness scale, Stanford sleepiness scale, Pittsburgh sleep quality scale. Besides, they measure sleepiness by combining objective measurement of multiple sleep diagrams with multiple sleep latency tests. However, the scale of sleepiness at work has been not made up. Therefore, it's very urgent to develop the scale of sleepiness at work and create the study methods. Such as interview, case study, field survey and laboratory study; and we also can do a survey with the qualitative and quantitative method. 


\subsection{Developing the Moderate Variables}

In the future, the moderate variables affecting sleeping need to be further explored. Individual differences may influence the relationship sleepiness with the work-relate variables. Physiology study shows that the sleep state will change with the age, and that personality traits (such as outgoing personality) can affect the outcome of sleep deprivation [31]. In addition, the different preferences for time types also affect the sleepiness at work. For example, night types may not perform at their peak during the day job assignments, and job design may be used to structure the workday to minimize sleepiness. But the moderated effect of preferences time types need the empirical study to verify.

\subsection{The Influence of Cultural Factors and Studying in China}

For the researchers and practitioners, the conclusion of the study in the west only has reference value, because different cultural backgrounds can bring different influential factors and intervention mechanism to sleepiness. Domestic theoretical and empirical researches on sleepiness at workplace are rare. With the development of economic globalization, developing domestic economy and the heavy working pressure, the sleepiness at work needs to explore in depth. In the future, we should face with the sleepiness challenges positively.

\section{Conclusion}

In summary, in order to avoid subsequent researchers confusing the similar concept with sleepiness, this paper clarified the concept of sleepiness at workplace, and respectively distinguished sleepiness at work with fatigue and narcolepsy. I believe that the following researchers will more accurately understand the concept of sleepiness at workplace. By reviewing and analyzing the previous studies, this paper delineated the causes and effects of sleepiness in the workplace. Among these studies, which main causes can mostly make employees fall asleep are time pressure, workload, perceived control, work schedules, and job rotation. It will lead to some negative results when employees being sleepiness at work, for example, poor information processing, more negative emotions, lower job performance, and increase in accidents. In a word, it is very important to study the sleepiness at workplace, especially for the manager. In order to maximize the interests of the company, managers must pay attention to the staff's sleepiness at work. In this article, we put forward some intervention measures from the level of individual and organization, and managers can learn from this article to deal with the problem of sleepiness at work. Because there are few researches on the sleepiness at work and still many aspects not developed very well, we put forward several research directions about the sleepiness at work, such as the diversification of research methods, developing the moderate variables. We hope that more researchers can keep on enriching the theoretical and empirical research about sleepiness at workplace in the future.

\section{References}

[1] Dou, W., Zhao, Z.X. and Huang, L.Q. (2005) Physical Effects of Sleep Restriction. Chinese Journal of Neuromedicine, 4, 748-751.

[2] Dement, W.C. and Carskadon, M.A. (1982) Current Perspectives on Daytime Sleepiness: The Issues. Sleep: Journal of Sleep Research \& Sleep Medicine, 5, S55-S56.

[3] Uehli, K., Mehta, A.J., Miedinger, D., Hug, K., Schindler, C., Holsboer-Trachsler, E., Leuppi, J.D. and Künzli, N. (2014) Sleep Problems and Work Injuries: A Systematic Review and Meta-Analysis. Sleep Medicine Reviews, 18, 6173. http://dx.doi.org/10.1016/j.smrv.2013.01.004

[4] Mullins, H.M., Cortina, J.M., Drake, C.L. and Dalal, R.S. (2014) Sleepiness at Work: A Review and Framework of How the Physiology of Sleepiness Impacts the Workplace. Journal of Applied Psychology, 99, 1096. http://dx.doi.org/10.1037/a0037885

[5] Xiong, J.D. and Liu, W. (2009) Sleep Disorder. The People’s Medical Publishing House.

[6] Shen, J., Barbera, J. and Shapiro, C.M. (2006) Distinguishing Sleepiness and Fatigue: Focus on Definition and Measurement. Sleep Medicine Reviews, 10, 63-76. http://dx.doi.org/10.1016/j.smrv.2005.05.004

[7] Balkin, T.J. and Wesensten, N.J. (2011) Differentiation of Sleepiness and Mental Fatigue Effects.

[8] Barnes, C.M. (2012) Working in Our Sleep: Sleep and Self-Regulation in Organizations. Organizational Psychology Review, 2, 234-257. http://dx.doi.org/10.1177/2041386612450181

[9] Bayard, S., Abril, B., Yu, H., Scholz, S., Carlander, B. and Dauvilliers, Y. (2011) Decision Making in Narcolepsy with 
Cataplexy. Sleep, 34, 99-104.

[10] Bower, B., Bylsma, L.M., Morris, B.H. and Rottenberg, J. (2010) Poor Reported Sleep Quality Predicts Low Positive Affect in Daily Life among Healthy and Mood-Disordered Persons. Journal of Sleep Research, 19, 323-332. http://dx.doi.org/10.1111/j.1365-2869.2009.00816.x

[11] Barnes, C.M., Ghumman, S. and Scott, B.A. (2013) Sleep and Organizational Citizenship Behavior: The Mediating Role of Job Satisfaction. Journal of Occupational Health Psychology, 18, 16. http://dx.doi.org/10.1037/a0030349

[12] Hamilton, N.A., Nelson, C.A., Stevens, N. and Kitzman, H. (2007) Sleep and Psychological Well-Being. Social Indicators Research, 82, 147-163. http://dx.doi.org/10.1007/s11205-006-9030-1

[13] Tucker, A.M., Whitney, P., Belenky, G., Hinson, J.M. and Van Dongen, H.P. (2010) Effects of Sleep Deprivation on Dissociated Components of Executive Functioning. Sleep, 33, 47-57.

[14] Wu, X.H. and Yuan, D.H. (2010) Adaptive Performance: A Domain Remains to Be Further Studied. Advances in Psychological Science, 2, 339-347.

[15] Hagewoud, R., Havekes, R., Tiba, P.A., Novati, A., Hogenelst, K., Weinreder, P., Van der Zee, E.A. and Meerlo, P. (2010) Coping with Sleep Deprivation: Shifts in Regional Brain Activity and Learning Strategy. Sleep, 33, 1465-1473.

[16] Zhou, H. (2011) Effect of Psychological Capital on Task Performance and Contextual Performance. Forum on Science and Technology in China, No. 7, 122-128.

[17] Van Der Helm, E., Gujar, N. and Walker, M.P. (2010) Sleep Deprivation Impairs the Accurate Recognition of Human Emotions. Sleep, 33, 335-342.

[18] Smith, M.J., Karsh, B.T., Carayon, P. and Conway, F.T. (2003) Controlling Occupational Safety and Health Hazards.

[19] Dinges, D.F. (1995) An Overview of Sleepiness and Accidents. Journal of Sleep Research, 4, 4-14. http://dx.doi.org/10.1111/j.1365-2869.1995.tb00220.x

[20] Drake, C., Roehrs, T., Breslau, N., Johnson, E., Jefferson, C., Scofield, H. and Roth, T. (2010) The 10-Year Risk of Verified Motor Vehicle Crashes in Relation to Physiologic Sleepiness. Sleep, 33, 745-752.

[21] Kling, R.N., McLeod, C.B. and Koehoorn, M. (2010) Sleep Problems and Workplace Injuries in Canada. Sleep, 33, 611-618.

[22] Demerouti, E., Bakker, A.B., Nachreiner, F. and Schaufeli, W.B. (2001) The Job Demands-Resources Model of Burnout. Journal of Applied Psychology, 86, 499-512. http://dx.doi.org/10.1037/0021-9010.86.3.499

[23] Åkerstedt, T., Knutsson, A., Westerholm, P., Theorell, T., Alfredsson, L. and Kecklund, G. (2002) Sleep Disturbances, Work Stress and Work Hours: A Cross-Sectional Study. Journal of Psychosomatic Research, 53, 741-748. http://dx.doi.org/10.1016/S0022-3999(02)00333-1

[24] De Lange, A.H., Kompier, M.A., Taris, T.W., Geurts, S.A., Beckers, D.G., Houtman, I.L. and Bongers, P.M. (2009) A Hard Day's Night: A Longitudinal Study on the Relationships among Job Demands and Job Control, Sleep Quality and Fatigue. Journal of Sleep Research, 18, 374-383. http://dx.doi.org/10.1111/j.1365-2869.2009.00735.x

[25] Kossek, E.E. and Michel, J. (2010) Flexible Work Schedules. Handbook of Industrial-Organizational Psychology, 1, 535-572.

[26] Drake, C.L. and Wright, K.P. (2011) Shift Work, Shift-Work Disorder, and Jet Lag. Principles and Practice of Sleep Medicine, 784-798. http://dx.doi.org/10.1016/B978-1-4160-6645-3.00071-2

[27] Tucker, P., Smith, L., Macdonald, I. and Folkard, S. (2000) Effects of Direction of Rotation in Continuous and Discontinuous 8 Hour Shift Systems. Occupational and Environmental Medicine, 57, 678-684. http://dx.doi.org/10.1136/oem.57.10.678

[28] Gumenyuk, V., Roth, T. and Drake, C.L. (2012) Circadian Phase, Sleepiness, and Light Exposure Assessment in Night Workers with and without Shift Work Disorder. Chronobiology International: The Journal of Biological and Medical Rhythm Research, 29, 928-936. http://dx.doi.org/10.3109/07420528.2012.699356

[29] Basner, M. and Dinges, D.F. (2009) Dubious Bargain: Trading Sleep for Leno and Letterman. Sleep, 32, 747-752.

[30] Fegley, S., Esen, E. and Schramm, J. (2010) Employee Benefits: Examining Employee Benefits in the Midst of a Recovering Economy.

[31] Killgore, W.D., Richards, J.M., Killgore, D.B., Kamimori, G.H. and Balkin, T.J. (2007) The Trait of IntroversionExtraversion Predicts Vulnerability to Sleep Deprivation. Journal of Sleep Research, 16, 354-363. http://dx.doi.org/10.1111/j.1365-2869.2007.00611.x 


\section{Submit or recommend next manuscript to SCIRP and we will provide best service for you:}

Accepting pre-submission inquiries through Email, Facebook, LinkedIn, Twitter, etc.

A wide selection of journals (inclusive of 9 subjects, more than 200 journals)

Providing 24-hour high-quality service

User-friendly online submission system

Fair and swift peer-review system

Efficient typesetting and proofreading procedure

Display of the result of downloads and visits, as well as the number of cited articles

Maximum dissemination of your research work

Submit your manuscript at: http://papersubmission.scirp.org/ 